\title{
Cocoa colonic phenolic metabolites are related to blood lipid lowering effects and methylxanthine metabolites and insoluble dietary fibre to anti-inflammatory and hypoglycemic effects in humans
}

\author{
Beatriz Sarriá ${ }^{\text {Corresp., } 1}$, Miren Gomez-Juaristi ${ }^{1}$, Sara Martínez López ${ }^{1}$, Joaquín García Cordero ${ }^{1}$, Laura Bravo ${ }^{1}$, Ma \\ Raquel Mateos Briz ${ }^{\text {Corresp. } 1}$ \\ ${ }^{1}$ Department of Metabolism and Nutrition, Institute of Food Science, Technology and Nutrition (ICTAN-CSIC); Spanish National Research Council (CSIC), \\ Madrid, España \\ Corresponding Authors: Beatriz Sarriá, Ma Raquel Mateos Briz \\ Email address: beasarria@ictan.csic.es, raquel.mateos@ictan.csic.es
}

Background. In many cocoa intervention studies, health outcomes are related to cocoa components without taking into account the bioavailability of the main bioactive components: phenolic compounds and methylxanthines.

Methods. The present work associates the results of bioavailability and randomised controlled crossover studies in humans carried out with similar cocoa products, so that the main phenol and methylxanthine metabolites observed in plasma and urine are associated to the health effects observed in the chronic studies. We outstand that doses of cocoa and consumption rate used are realistic. In the bioavailability study, a conventional (CC) and methylxanthine-polyphenol rich (MPC) cocoa product were used, whereas in the chronic study a dietary fibre-rich (DFC) and polyphenol-rich (PC) product were studied in healthy and cardiovascular risk subjects.

Results and Discussion. The main phenolic metabolites formed after CC and MPC intake, 5-(4'hydroxyphenyl)- $\gamma$-valerolactone-3'-sulfate, 3'-methyl-epicatechin-5-sulfate, 4-hydroxy-5-(4'hydroxyphenyl)valeric acid-sulfate, 5-phenyl- $\gamma$-valerolactone--sulfate and 5-(4'-hydroxyphenyl)- $\gamma$ valerolactone-3'-glucuronide, may contribute to the changes in cholesterol (and indirectly HDLcholesterol) observed after the regular intake of both DFC and PC, in healthy and cardiovascular risk subjects. Whereas, 7-methylxanthine (the main cocoa methylxanthine metabolite) and theobromine, together with its content in insoluble dietary fiber, may be responsible for the decrease of IL-1 $\beta$ and hypoglycemic effects observed with DFC. With both phenolic and methylxanthine metabolites a strong dose-response effect was observed.

Conclusion. After the regular consumption of both DFC and PC, positive changes were observed in volunteer's lipid profile, which may be related to the long-lasting presence of colonic phenolic metabolites in blood. In contrast, the anti-inflammatory and hypoglycemic effects were only observed with DFC, and these may be related to methylxanthine metabolites, and it is likely that insoluble dietary fibre may have also played a role. 
1 Cocoa colonic phenolic metabolites are related to blood lipid lowering effects and 2 methylxanthine metabolites and insoluble dietary fibre to anti-inflammatory and 3 hypoglycemic effects in humans

4

5 Beatriz Sarriá*, Miren Gómez-Juaristi, Sara Martínez-López, Joaquín García-Cordero, 6 Laura Bravo-Clemente and Raquel Mateos*

7 Department of Metabolism and Nutrition, Institute of Food Science, Technology and 8 Nutrition (ICTAN-CSIC). Spanish National Research Council (CSIC), José Antonio 9 Nováis 10, 28040 Madrid, Spain.

10

11

Corresponding Authors:

Beatriz Sarriá and Raquel Mateos

Department of Metabolism and Nutrition, Institute of Food Science, Technology and Nutrition (ICTAN-CSIC). Spanish National Research Council (CSIC), José Antonio Nováis 10, 28040 Madrid, Spain Beatriz Sarriá (beasarria@ictan.csic.es); Raquel Mateos (raquel.mateos@ictan.csic.es)

\section{Abstract}

Background. In many cocoa intervention studies, health outcomes are related to cocoa components without taking into account the bioavailability of the main bioactive components: phenolic compounds and methylxanthines.

Methods. The present work associates the results of bioavailability and randomised controlled crossover studies in humans carried out with similar cocoa products, so that the main phenol and methylxanthine metabolites observed in plasma and urine are associated to the health effects observed in the chronic studies. We outstand that doses of cocoa and consumption rate used are realistic. In the bioavailability study, a conventional (CC) and methylxanthine-polyphenol rich (MPC) cocoa product were used, whereas in the chronic study a dietary fibre-rich (DFC) and polyphenol-rich (PC) product were studied in healthy and cardiovascular risk subjects. 
31 Results and Discussion. The main phenolic metabolites formed after CC and MPC 32 intake, 5-(4'-hydroxyphenyl)-y-valerolactone-3'-sulfate, 3'-methyl-epicatechin-5-sulfate, 4-hydroxy-5-(4'-hydroxyphenyl)valeric acid-sulfate, 5-phenyl-y-valerolactone--sulfate

34 35 36 and 5-(4'-hydroxyphenyl)- - -valerolactone-3'-glucuronide, may contribute to the changes in cholesterol (and indirectly HDL-cholesterol) observed after the regular intake of both DFC and PC, in healthy and cardiovascular risk subjects. Whereas, 7-methylxanthine (the main cocoa methylxanthine metabolite) and theobromine, together with its content in insoluble dietary fiber, may be responsible for the decrease of IL-1 $\beta$ and hypoglycemic effects observed with DFC. With both phenolic and methylxanthine metabolites a strong dose-response effect was observed.

Conclusion. After the regular consumption of both DFC and PC, positive changes were observed in volunteer's lipid profile, which may be related to the long-lasting presence of colonic phenolic metabolites in blood. In contrast, the anti-inflammatory and hypoglycemic effects were only observed with DFC, and these may be related to methylxanthine metabolites, and it is likely that insoluble dietary fibre may have also played a role.

\section{Abbreviation list}

Body Mass Index (BMI)

Caffeine (CF)

Catechin (CA)

Conventional cocoa (CC)

Dietary fiber (DF)

Dietary fiber-rich cocoa (DFC)

Epicatechin (EC)

Insoluble DF (IDF)

Malondialdehyde (MDA)

Methyluric acid (MU)

Methylxanthine-polyphenol rich cocoa (MPC)

Paraxanthine (PX)

Polyphenol-rich cocoa (PC) 
62 Procyanidin B1 (PB1)

63 Procyanidin B2 (PB2)

64 Raw cocoa (RC)

65 Soluble DF (SDF)

66 Theobromine (TB)

67 Theophylline (TP)

68 Trolox Equivalent (TE)

69 5-(3',4'-Dihydroxyphenyl)-y-valerolactone (DHPVL)

70 4-Hydroxy-5-(Hydroxyphenyl)valeric acid sulfate (HHPVA-sulfate)

71 5-(4'-Hydroxyphenyl)-y-valerolactone-3'-sulfate (HPVL-3'-sulfate)

72 5-(4'-Hydroxyphenyl)- $\gamma$-valerolactone-3'-glucuronide (HPVL-3'-glucuronide)

73 5-(Phenyl)-y-valerolactone-sulfate (PVL-sulfate)

74

75

76 Introduction

77 Cocoa is consumed worldwide in different population groups being Europe the world's 78 largest cocoa consuming area with a $40 \%$ of global consumption (Food and Agricultural Organization of the United Nations, 2003). In response to consumer's demand, the food industry continues producing functional cocoa products enriched with bioactive components, such as dietary fibre, polyphenols or methylxanthines, or making products without fat, sugar or sweeteners (World Cocoa Conference, 2018).

A body of scientific evidence supports the beneficial cardiovascular health effects of cocoa consumption (Arranz et al., 2013; Ellam \& Williamson, 2013; Gómez-Juaristi et al., 2011; Hooper et al., 2012). However, there are aspects in cocoa's health effects that need to be clarified. The aim of this work is to look into the effects of cocoa on cardiovascular health through associating the lipid lowering, anti-inflammatory and hypoglycemic effects observed in two chronic, randomized, controlled studies, with the phenolic and methylxanthine metabolites observed in bioavailability studies in humans with similar cocoa products. It is noteworthy that the cocoa products used in both the chronic and bioavailability studies, produced by the same cocoa manufacturer, had a 
92 similar cocoa matrix and realistic amounts of cocoa were consumed by the volunteers in 93 both studies.

94 In many cocoa intervention studies, health outcomes are related to cocoa component 95 intake without taking into account the bioavailability of the main bioactive components in 96 the test food. The present work goes one step ahead and considers the bioavailability of 97 two of the main bioactive components in cocoa products: the phenolic compounds, 98 mainly flavanols epicatechin, catechin and procyanidins (Gómez-Juaristi, et al., 2019) 99 as well as methylxanthines, mainly theobromine followed by theophylline and caffeine 100 (Martínez-López et al., 2014a). The main metabolites observed in plasma and urine are

101

102 103

104

105

106

107

108

109

110

111

112

113

114

115

116

117

118

119

120

121 related to the health effects observed in two randomised controlled human studies carried out with cocoa products similar to that used in the bioavailability study, i.e. a functional cocoa product rich in dietary fibre (Sarriá et al., 2014) and a cocoa product rich in polyphenols (Martínez-López et al., 2014b). As said, the cocoa products used in the mentioned studies were provided by a well-known Spanish cocoa product manufacturer who prepared individual sachets containing the dose recommended on the label to prepare the chocolate drink. It is important to note that the doses used are realistic, contrary to many studies that use exaggerated cocoa conditions. Moreover, the consumption rate corresponds to a real consumption pattern, two sachets per day.

\section{Materials \& Methods}

\section{Characterisation of the cocoa products}

Five cocoa powders were analyzed, an un-processed cocoa powder (cocoa RC), and four new soluble cocoa products commercially available in Spain: cocoa DFC [rich in dietary fibre (DF)], cocoa MPC (rich in methylxanthines and cocoa), cocoa CC [conventional cocoa low in sugar (2.8)], and cocoa PC [rich in cocoa, and thus phenolic compounds, and low in sugar (2.8\%)].

In all the cocoa products studied, polyphenols and methylxanthines were extracted following a procedure developed by our group (Bravo \& Saura-Calixto, 1998). Total polyphenols were determined using Folin-Ciocalteau reagent and gallic acid as standard and the phenolic and methylxanthine composition of the cocoa extracts was 
122 characterized by high-performance liquid chromatography (HPLC) with diode-array 123 detection (DAD) using an Agilent 1200 series equipment, the procedure followed is 124 described in Gomez-Juarist et el., (2019).

125 The total DF of the cocoa products was analyzed in triplicate from defatted samples 126 following the AOAC method modified in our laboratory (Saura-Calixto et al., 2000) and 127 is described in Sarriá et al., (2012).

128 The antioxidant capacity of the all the cocoa products was evaluated in the soluble 129 extracts by three different methods. The reducing power of the samples was measured 130 using the ferric reducing/antioxidant power (FRAP) assay (Pulido, Bravo \& Saura131 Calixto, 2000). The capacity of samples to scavenge the stable radical ABTS was 132 determined by the ABTS discoloration method (Re et al., 1999). And the oxygen radical 133 absorbance capacity (ORAC) was determined according to (Huang et al, 2002). In the 134 three parameters, Trolox was used as standard and results were expressed as $\mu \mathrm{mol}$ of 135 Trolox Equivalent (TE) per gram of dry matter (d.m.) of the product. Additionally, the 136 FRAP and ABTS methods were also used to determine the antioxidant capacity in 137 serum samples obtained in the bioavailability study (see below), and results were expressed as $\mu \mathrm{M}$ TE.

\section{Methylxanthine and polyphenol bioavailability studies}

141

142

143

144

145

A crossover, single-blind study was carried out in healthy men and women, aged 18-45 years old, with body mass index between 18 and $25 \mathrm{~kg} / \mathrm{m}^{2}$. They were also non-smoker, non-vegetarian, non-pregnant women, who were not taking any medication or nutritional supplements, not suffering from any chronic pathology or gastrointestinal disorder. Fourteen volunteers gave their written informed consent prior to participation in the bioavailability study, but only thirteen completed the study.

On two different days, separated by a 10-day period, after an overnight fast, volunteers consumed $15 \mathrm{~g}$ of the conventional cocoa product low in sugar (CC) and $25 \mathrm{~g}$ of a cocoa product enriched in methylxanthines and polyphenols (MPC) in $200 \mathrm{~mL}$ of semi- 
150 skimmed milk. A nurse inserted a cannula in the cubital vein of one of their arms and 151 blood samples were collected into EDTA-coated tubes at baseline $(t=0)$ and $0.5,1,2,3$, 1524,6 and $8 \mathrm{~h}$ after consuming the cocoa drinks and plasma was separated by 153 centrifugation. Analytical methods were optimized to measure by chromatography the 154 absorption of methylxanthines and phenolics in plasma. The two days previous to each 155 intervention, certain polyphenol-rich-foods, such as some fruits, vegetables and their derivate beverages, as well as methylxanthine-rich-foods, such as coffee, tea or chocolate products, were restricted from their diets in order to reduce inter and intraindividual differences. Volunteers were asked to complete a $24 \mathrm{~h}$ food intake recall the day before each intervention in order to control any possible food restriction incompliance. The bioavailability studies of polyphenols and methylxanthines in the cocoa products have already been described in detail in Gómez-Juaristi et al., (2019) and Martinez-López et al., (2014a).

\section{Chronic cocoa studies}

165

166

167

168

169

170

171

172

173

174

175

176

To evaluate the effects of regularly consuming DFC (Sarriá et al., 2014) and PC (Martínez-López et al., 2014b) on markers of cardiovascular health, two controlled, randomized, crossover studies were carried out in free-living healthy and moderately hypercholesterolemic (2000-2400 mg/L; 5.172-6.206 mmol/L). In both studies the inclusion criteria was: men and women (not including pregnant women), between 18-55 y old, with body mass index $(\mathrm{BMI})<30 \mathrm{~kg} / \mathrm{m}^{2}$, non-vegetarian, non-smoker, not suffering from any chronic pathology or gastrointestinal disorder. Briefly, each study consisted in a run-in (2 weeks), a control and cocoa intervention (4 weeks each). In Sarriá et al., (2014) volunteers consumed twice a day $15 \mathrm{~g}$ of DFC (30 g/day) and in Martínez-López et al., (2014b), two times a day $7.5 \mathrm{~g}$ per serving of PC (15 g/day). Along both studies other cocoa products, certain fruits and vegetables rich in polyphenols were restricted. Forty four subjects completed both studies, among these were the 13 subjects who carried out the bioavailability study. 
179 Blood samples, blood pressure, heart rate and anthropometric measurements were 180 taken at baseline and at the end of each intervention. In blood samples, biochemical, 181 inflammatory, oxidation and antioxidant biomarkers were measured, for more details 182 please see Sarriá et al., (2014) and Martínez-López et al., (2014b).

183 Both chronic and bioavailability studies were conducted according to the guidelines laid 184 down in the Declaration of Helsinki and all procedures were approved by the Clinical Research Ethics Committee of Hospital Universitario Puerta de Hierro Majadahonda in Madrid (Spain). Approvals were obtained by this Hospital because all human studies carried out in Consejo Superior de Investigaciones Cientifícias (CSIC) are submitted to the Ethics Committee of Hospital Puerta de Hierro, unless there are participants in the project who are affiliated to a hospital with an Ethics Committee, but in the present study this was not the case. Volunteer recruitment was carried out through placing advertisements in the Universidad Complutense campus as well as through giving short talks between lectures.

193

194

196

197

\section{Results and Discussion}

In the recent years, a Spanish cocoa manufacturer has been producing new soluble, powder, cocoa products with added value increasing the content in bioactive compounds, specifically flavanols, dietary fibre and methylxanthines, and lowering the sugar levels trying not to compromise the flavour and texture of the cocoa products but to keep or improve health effects.

Certainly, in cocoa and most cocoa products, the main bioactive components are phenolic compounds, methylxanthines and dietary fibre. Therefore, phenolic compound and methylxanthine bioavailability studies were carried out in humans, using realistic amounts of cocoa products from the same cocoa manufacturer with the purpose to better understand the metabolism of these components and to establish a relationship between the main cocoa phenolic and methylxanthine metabolites (Gómez-Juaristi et al., 2019; Martínez-López et al., 2014a) and the biological effects observed in chronic studies (Sarriá et al., 2014; Bravo \& Saura-Calixto, 1998). 


\section{Characterization of cocoa products}

209 The polyphenolic composition, according to the Folin-Ciocalteau assay and HPLC-DAD 210 analysis, the methylxanthine and dietary fibre composition are shown in Table 1. Cocoa 211 powder RC showed the highest total polyphenol content which may be explained 212 because product RC is naturally rich, non-processed cocoa. Among the commercialized 213 cocoa rich products, cocoa powder PC showed the highest level of total polyphenols 214 followed by cocoa products MPC and CC, whereas product DFC, which was rich in DF 215 but not in cocoa, showed the lowest polyphenol content. According to the results 216 obtained in cocoa RC and DFC, it seems that the manufacturing process lowers the 217 content of polyphenols approximately $62.6 \%$ and from this point cocoa enrichment has taken place to different extents to reach the polyphenol levels described in products PC, CC and MPC. Chromatographic analyses of the cocoa products studied showed that, among the monomeric flavanols, epicatechin (EC) was the most abundant, between 0.33-2.40 $\mathrm{mg} / \mathrm{g}$ d.m., whereas catechin (CA) ranged between $0.26-0.83 \mathrm{mg} / \mathrm{g} \mathrm{d}$.m. and, among the dimeric compounds the most abundant was procyanidin B2 (PB2), 0.39-2.04 $\mathrm{mg} / \mathrm{g}$ d.m., whereas procyanidin B1 (PB1) was between 0-0.41 $\mathrm{mg} / \mathrm{g} \mathrm{d} . \mathrm{m}$. It is noteworthy that the "natural" content of total polyphenols obtained in product $\mathrm{R}$ is not reached by any of the cocoa enriched products. EC and CA contents observed in the natural cocoa powder were similar to those described by Miller et al., (2009) in other cocoa products.

Since many years ago, it has been established that food antioxidant capacity is strongly related to its polyphenol content (Benzie \& Szeto, 1999). In accordance, in the present work the phenolic content of the studied cocoa powders was directly proportional to the antioxidant activity assessed using FRAP, ABTS and ORAC assays (Table 2), so that FRAP results were 5 times higher than the total polyphenol content of the cocoa products, whereas ABTS and ORAC results were 3-4 and 10-14 times higher, respectively. Taking the present results into account, consuming a dose of $15 \mathrm{~g} / \mathrm{d}$ of cocoa PC as recommended by the manufacturer would yield 2626 (FRAP method), 1996 (ABTS method) or 3855 (ORAC method) $\mu \mathrm{mol}$ Trolox equivalents (TE) of 
238 (FRAP) and 1328 (ABTS) $\mu \mathrm{mol}$ Trolox equivalents, respectively] or red wine [601 239 (FRAP) and 631 (ABTS) $\mu \mathrm{mol}$ Trolox equivalents, respectively], which are the 240 beverages that have been described to have the highest antioxidant capacity within the 241 Mediterranean diet by Saura-Calixto \&Goñi (2006).

242 Furthermore, soluble cocoa products are also a relevant source of DF, in contrast to 243 chocolate, due to DF being largely discarded in its production (Jenkins et al., 2000).

244 Dietary guidelines recommend a minimum daily intake of DF of $25 \mathrm{~g}$

245 (https://health.gov/dietaryguidelines/2015/), which is considerably higher than the 246 estimated intakes in Western countries (Jenkins et al., 2000). Bearing this in mind, the 247 food industry prompted the production of dietary fibre rich foods, such as cocoa product 248 DFC. In all products, insoluble DF (IDF) was the predominant fraction, varying between 24973 and $92 \%$ of the total DF content, which is in agreement with previous results 250 (Lecumberri et al., 2007) that showed that the main polysaccharides in cocoa IDF were 251 cellulose, hemicellulose and some pectic substances, while cocoa soluble DF (SDF) 252 was composed mainly of pectins and minor amounts of galactomannans.

253 As for the different cocoa products, it is noteworthy that cocoa product MPC, which is 254 rich in polyphenols and methylxanthines, showed the highest content in total DF $(30 \%)$, 255 even higher than the fibre-rich cocoa product DFC, which contained $22 \%$ total DF. Both 256 products DFC (92\%) and MPC (90\%) presented a similar proportion of IDF (IDF) with 257 respect to total DF (Table 1). The contribution of SDF to the total dietary fibre was highest in product RC (27\%) followed by product PC $(20.7 \%)$. Interestingly, SDF content in the cocoa products followed the same order than the antioxidant capacity and their 260 total flavanol content $(\mathrm{R}>\mathrm{PC}>\mathrm{MPC}>\mathrm{CC}>\mathrm{DFC})$.

261 Regarding the methylxanthine contents in cocoa, theobromine was the primary 262 methylxanthine in all the tested cocoa products (Table 1), followed by caffeine, in 263 agreement with the literature (Carlin-Sinclair \& Marc, 2009). Cocoa MPC was the 264 product with the highest content in total methylxanthines, being particularly rich in caffeine, as this product was enriched in kola nut, which is a source of caffeine. Theophylline was only found in products MPC and R, and scarcely in PC, whereas in the other cocoa products the concentrations were under the limit of detection. Cocoa is 
268 also a source of caffeine. A $15 \mathrm{~g}$ serving of cocoa MPC would provide $153.6 \mathrm{mg}$ of 269 methylxanthines (69\% theobromine and $29.5 \%$ caffeine), which is similar to the amount 270 of caffeine provided per serving in $330 \mathrm{~mL}$ of a cola drink ( $40 \mathrm{mg}$ ).

271

\section{Bioavailability and metabolism}

273 It is essential to better understand the bioavailability and metabolism of the main 274 bioactive compounds in cocoa, i.e. polyphenols. However, another question that needs 275 to be further clarified is what other compounds in cocoa, beyond flavanols, are 276 responsible for the beneficial health effects. In this context, methylxanthines constitute 277 another outstanding group of bioactive compounds in cocoa products, although less 278 considered when biological effects of cocoa products on health are discussed. For this 279 reason, it is relevant to explore the main metabolites formed from methylxanthines' 280 bioavailability along with the metabolites derived from metabolism of flavanols, as it can 281 help to better explain the compounds responsible of the health effects associated to 282 cocoa consumption and the involved mechanisms.

283 In the bioavailability studies presented in this work, a main objective was, besides 284 establishing flavanols and methylxanthines absorption and metabolism after intake of 285 realistic doses of cocoa products, to assess if there was a dose-dependent response. 286 Therefore, the product which showed the highest amount of methylxanthines of all the 287 288 cocoa products and which was rich in polyphenols (MPC) was selected to compare with the conventional product (CC).

\section{Methylxanthines}

291 The absorption and metabolism of methylxanthines present in the two tested soluble 292 cocoa products, CC corresponding to the conventional cocoa low in sugar and MPC 293 enriched in methylxanthines and polyphenols, was evaluated in healthy subjects (Martínez-López et al., 2014a). The main methylxanthines and their plasma and urine 
296 of CC and $25 \mathrm{~g}$ of MPC, in $200 \mathrm{~mL}$ of milk) with different methylxanthine composition:

297 CC provided $84.45 \mathrm{mg}$ of theobromine (TB) and $9.9 \mathrm{mg}$ of caffeine (CF) while MPC 298 provided $177 \mathrm{mg} \mathrm{TB}, 75.75 \mathrm{mg} \mathrm{CF}$ and $3.25 \mathrm{mg}$ theophylline (TP).

299 Metabolism of cocoa methylxanthines in humans has not been widely studied and some 300 results obtained by our group were novel findings. Up to 12 different metabolites were

301

302

303

304

305

306

307

308

309

310

311

312

313

314

315

316

317

318

319

320

321

322

323

324 identified and quantified in a single run in biological fluids by HPLC-DAD and LC-QTOF. On one hand, TB, CF, TP and paraxanthine (PX) together with two monomethylxanthines (3-methylxanthine (MX) and 7-methylxanthine) were identified and quantified in plasma by HPLC-DAD.TB the most abundant plasmatic compound of all the identified metabolites, followed by TP and PX with similar levels. These compounds were rapidly detected in plasma, showing their maximum concentration $\left(C_{\max }\right)$ between 1 to 4 hours after ingestion and maintaining similar levels throughout 8 $h$, not returning to basal levels in this period. The maximum concentration $\left(C_{\max }\right)$ and area under curve (AUC) values of all metabolites were significantly higher after the intake of MPC, showing a dose-dependent response.

These metabolites together with 1-methylxanthine and different mono-, di- and trimethyluric (MU) acids (1-MU, 1,3-MU, 1,7-MU, 3,7-MU and 1,3,7-MU) involved in the biotransformation of the ingested methylxanthines were detected by LC-QTOF and quantified by LC-DAD in urine, with 7-MX as the most abundant metabolite followed by TB and 3-MX (Figure 1). Most metabolites were extensively excreted in urine between 4 and 8 hours after CC and MPC intake; although similar to the behaviour described in plasma, higher levels of excreted metabolites were observed until $24 \mathrm{~h}$ post-intake. Results showed a strong dose-response effect after cocoa consumption at the doses tested, up to $256 \mathrm{mg}$ of MX. It can be concluded that methylxanthines in cocoa are bioavailable, partially metabolized and rapidly eliminated, with a sustained urinary excretion for as long as $24 \mathrm{~h}$ after intake. The long permanence of methylxanthines and their metabolites in body fluids favours the involvement of these compounds on the health effects associated to cocoa products consumption.

\section{Polyphenols}


326 Although there are many bioavailability studies of cocoa flavanols, most of them have 327 been carried out with unrealistic doses (Ottaviani et al., 2012a; Ottaviani et al., 2012b; 328 among others). Addressing the need to carry out studies that follow realistic

329

330

331

332

333

334

335

336

337

338

339

340

341

342

343

344

345

346

347

348

349

350

351

352

353

354

355

356

consumption guidelines to further understand the bioavailability and metabolism of real doses of flavanols, which may differ from higher doses used in previous articles, a recent clinical intervention study was performed in our research group (Gómez-Juaristi et al., 2019). This study was aimed at assessing in healthy humans the absorption and metabolism of polyphenols in a single, realistic dose of CC (15 g) and MPC (25 g), which provided $19.8 \mathrm{mg}$ and $68.25 \mathrm{mg}$ of flavanols, respectively.

Blood and urine samples were taken before and after CC and MPC consumption and analyzed by LC-MS-QToF. Up to 10 and 30 metabolites were identified in plasma and urine, respectively. Among the metabolites identified, phase II derivatives of epicatechin showed the maximum concentration in plasma from 1 to $2 \mathrm{~h}$ after ingestion and kinetics compatible with their absorption at small intestine. 3'-Methyl-epicatechin-5-sulfate and epicatechin-3'-sulfate were the predominant metabolites followed by 4'-methylepicatechin-5-sulfate, and epicatechin-3'-glucuronide among others. Phase II derivatives of epicatechin accounted for approximately $33 \%$ of total urinary metabolites. The most abundant group of metabolites were phase II derivatives of hydroxyphenyl- $\gamma$ valerolatones and valeric acid, formed at colonic level as $5 \mathrm{C}$-ring fission metabolites by microbiota-mediated (Figure 1). These compounds showed a delayed kinetic due to their colonic origin and represented the most abundant group of metabolites $(67 \%$ of total urinary metabolites) headed by 5 -(4'-hydroxyphenyl)- $\gamma$-valerolactone-3'-sulfate (HPVL-3'-sulfate) followed by 4-hydroxy-5-(hydroxyphenyl)valeric acid sulfate (HHPHVA-sulfate), 5-(phenyl)-y-valerolactone--sulfate (PVL--sulfate), 5-(4'hydroxyphenyl)-y-valerolactone-3'-glucuronide (HPVL-3'-glucuronide) and 5-(3',4'dihydroxyphenyl)- $y$-valerolactone (DHPVL), among others. According to these results, HPVL-3'-sulfate could be a sensitive biomarker of flavanol intake, considering its abundance in urine, amounting up to $40 \%$ of total urinary metabolites. Flavanols of CC and MPC showed a dose-dependent absorption with a recovery value of $35 \%$ of the ingested dose. 
357 The relationship between the main cocoa metabolites and the cardiovascular 358 health effects

359 To understand the health effects of cocoa or cocoa-based functional products, it is 360 important to carry out randomized controlled human studies using normal, realistic 361 doses of the food products. Such aspects were considered in two chronic studies 362 carried out in our research group; in the first, the regular consumption of a cocoa 363 product rich in dietary fibre (DFC) (Table 3) during 4 weeks led to a significant increase 364 in HDL-cholesterol and a decrease in glucose and IL-1 $\beta$ without producing changes in 365 body weight neither other anthropometric parameters studied (Sarriá et al., 2014); in the 366 second, the sustained consumption of the cocoa product rich in cocoa (PC) (Table 3) for 367 the same length of time, 4 weeks, resulted in an increase in HDL-cholesterol without 368 other changes in cardiovascular related biomarkers (Martínez-López et al., 2014b).

369 When the health effects of both cocoa products were comparatively studied in relation 370 to the amounts of bioactive compounds consumed, without considering the 371 bioavailability of these compounds, on one hand, mainly the flavanol content provided 372 by both cocoa products was related to the increase in HDL-cholesterol, and on the other 373 hand, the IDF and theobromine were associated to the hypoglycemic and anti374 inflammatory effects observed after consuming the fibre rich product (Sarriá et al., 375 2015). However, as aforementioned, the present study goes one step ahead and further 376 looks into the relationship between the main phenolic and methylxanthine metabolites 377 observed in bioavailability studies in humans, carried out using similar cocoa products 378 to those used in the crossover, intervention studies.

379

Main phenolic metabolites after cocoa consumption in humans and their health effects

a) Epicatechin and phase II derivatives

383

384

385

Numerous human dietary intervention studies link the consumption of flavan-3-ols derived from cocoa to improved cardiovascular health (Heiss, Keen \& Kelm, 2010; Rodriguez-Mateos et al., 2014), having epicatechin and its phase II derivatives, at least 
386 partially, been linked with these beneficial effects (Borges et al., 2018). In contrast to the 387 results of Dower et al., (2015), who investigated the effects of pure epicatechin 388 supplementation and described no effects on cholesterol, many other studies have

389

390

391

392

393

394

395

396

397

398

399

400

401

402

403

404

405

406

407

408

409

410

411

412

413

414

415

416 correlated the consumption of products rich in epicatechin with a decrease in serum levels of LDL-cholesterol in both hypercholesterolemic subjects (Grassi et al., 2005) and healthy subjects (Baba et al., 2007). The mechanisms responsible for the decrease in the levels of LDL include: inhibiting cholesterol absorption in the gut, reducing cholesterol synthesis by decreasing the activity and/or expression of hydroxymethylglutaryl coenzyme A (HMG-CoA) synthase, HMG-CoA reductase, sterol O-aciltransferase and microsomal triglyceride transport protein in the liver, suppressing hepatic secretion of apolipoprotein B100, increasing the expression of hepatic LDL receptors, and preventing oxidation of LDL (Baba et al., 2007). Separately, epicatechin and catechin, which have similar biological activity, have also shown to raise the concentration of HDL-cholesterol through the increased expression of scavenger receptor B type I (SR-BI), sterol regulatory element binding proteins (SREBPs), ATP binding cassette transporter $\mathrm{A} 1$ (ABCA1) or apolipoprotein A1, among others (MartínezLópez et a., 2014b). Moreover, Rodriguez-Mateos et al., (2018) recently described that cocoa consumption in healthy humans induced effects on flow mediated dilatation, pulse wave velocity and blood pressure mediated by EC metabolites and not DHPVL metabolites.

In addition, it is important to emphasize epicatechin's antioxidant function, being able to adhere to LDL particles or apolipoprotein B and to recycle molecules of a-tocopherol donating a hydrogen atom, thus maintaining the concentration of endogenous antioxidants for longer time (Wan et al., 2001). This property, combined with the reduction of iron (non-heme) and malondialdehyde (MDA) concentrations and the suppression of pro-oxidant enzymes, have been described to be responsible for the increase in blood antioxidant activity after epicatechin consumption (Prakash, Basavaraj \& Murthy 2019). However, not all phase II metabolites have the same antioxidant activity. Epicatechin and its 7-O-glucuronide derivative show a similar reduction in LDL oxidation, unlike 3'-O-glucuronide and 4'-O-methyl-3'-O-glucuronide derivatives, which show lower activity. Similarly, the O-methylated derivatives C-3' and C-4'-O-methyl ether 
417 of epicatechin are less active than their base compound. Moreover, it should not be 418 disregarded that the antioxidant activity of these metabolites is dependent on the $\mathrm{pH}$ of 419 the medium, so that at 7.4 their activity is largely retained, which confirms their 420 antioxidant action in physiological conditions (Monagas et al., 2010).

421 There is controversy regarding the hypoglycaemic activity of epicatechin and its 422 derivatives. According to Rodriguez-Mateos et al., (2018), there were no effects of 423 epicatechin or procyanidins on fasting glucose concentration. In contrast, a study 424 conducted by Josic et al., (2010) in healthy subjects showed that consumption of green 425 tea rich in epicatechin reduced glucose and insulin concentration. The main pathway by which epicatechin and its derivatives exert this effect is through increased sensitivity to insulin in hepatic or adipose cells, in which epicatechin inhibits the action of different signalling proteins such as PKCD, IKK, JNK, NF-KB and PTP-18, which leads to a decrease in insulin resistance (Cremonini et al., 2016). In addition, a recent study in mice has observed that the consumption of a food rich in epicatechin promotes the regeneration of cells $\beta$-pancreatic (Prakash, Basavaraj \& Murthy 2019).

5-(3',4'-dihydroxyphenyl)-y-valerolactone (DHPV) is a compound resulting from the degradation of procyanidins or monomers that may reach the colon and be cleaved by the colonic microbiota (Appeldoorn et al., 2009; Fogliano et al., 2011). Its antioxidant capacity has been tested in vitro, being superior to catechin, ascorbic acid and Trolox (vitamin E analogue; Appeldoorn et al., 2009).

438 Up to date, hardly any in vivo study has been conducted to demonstrate the effect of 439 DHPVL on lipid and glycaemic metabolism. Only by extrapolating the results obtained in 440 clinical studies with products rich in procyanidins, such as cocoa (Sarriá et al., 2014; 441 Martínez-López et al., 2014b; Sarriá et al., 2015; Grassi et al., 2005; Baba et al., 2007; 442 Khan et al., 2012), with its antioxidant capacity (Khan et al., 2012), and considering the 443 fact that it is one of the main metabolites found in blood after the consumption of cocoa 444 (Urpi-Sarda et al.,2009a; Urpi-Sarda et al., 2009b) it has been deduced that DHPVL 445 has hypolipemic and hypoglycemic properties. This is in agreement with the results 
446 obtained by Rodriguez-Mateos et al., (2018), who described that the consumption of 447 cocoa procyanidins induced a health benefit in healthy humans related to the reduction 448 of total cholesterol, having an impact on cholesterol absorption and faecal steroid

449 450

451

452

453

454

455

456

457

458

459

460

461

462

463

464

465

466

467

468

469

470

471

472

473

474 excretion inside the gastrointestinal tract. This effect was particularly linked to procyanidins content, which are metabolized into DHPVL and its phase II derivatives.

Recently, a study carried out in rabbits with obesity and non-alcoholic fatty liver suggested that the effects of procyanidins, metabolized into DHPV derivatives, were due to changes in the intestinal microbiota. In fact, the supplementation with procyanidin B2 decreased the ratio Firmicutes/Bacteroidetes and increased the proportion of Akkermansia, which has the ability to maintain the thickness of intestinal mucus, reducing the permeability to lipopolysaccharides (LPS) and thus relieving inflammation. As a consequence of the maintenance of the intestinal barrier, a decrease in the concentration of LPS in serum was observed, which may explain the reduction in the accumulation of triglycerides in the liver and the protection against non-alcoholic fatty liver (NAFLD) (Xiang et al., 2019).

According to the results on phenolic metabolites (Table 3), it may be proposed that the main metabolites observed after intake of CC and MPC (HPVL-3'-sulfate, 3'-methylepicatechin-5-sulfate, HHPHVA-sulfate, PVL--sulfate and HPVL-3'-glucuronide), may be responsible for certain changes observed in the chronic studies with DFC and PC. Specifically, to the changesin cholesterol, and indirectly HDL-cholesterol, observed after regular intake of DFC or PC in both healthy and cardiovascular risk subjects.

Regarding the effects of the cocoa products on serum antioxidant capacity, along the bioavailability study, there were no significant differences between the two cocoa products according to the estimations carried out with FRAP method except at $2 \mathrm{~h}$ $(p=0.039)$ and $6 \mathrm{~h}(p=0.044)$, and according to ABTS at $1 \mathrm{~h}(p=0.004)$ with MPC higher than CC (Table 4). In agreement, no significant differences in serum antioxidant capacity, measured by ORAC, FRAP and ABTS as well as levels of protein (carbonyl groups) and lipid (MDA), were observed in the chronic interventions (Sarriá et al., 2014; Martínez-López et al., 2014b). 
Main methylxanthine metabolites after cocoa consumption in humans and their health effects

478

479

480

481

482

483

484

485

486

487

488

489

490

491

492

493

494

495

496

497

498

499

500

501

502

503

All the methylxanthine compounds have in common the capacity to act as

phosphodiesterase inhibitors, modulators of GABA and adenosine receptors, as well as to regulate intracellular calcium levels (Williams et al., 1978; Monteiro et al., 2016). However, Williams et al., (1978) described many years ago that there are certain differences in the inhibitory and regulatory activity, with theophylline and 3methylxanthine having greater activity than caffeine and 1-methylxanthine.

Traditionally, the HDL cholesterol raising effect of cocoa has been associated with cocoa flavonols (Baba et al., 2007; Mellor et al., 2010; Neufingerl et al., 2013). Nevertheless, methylxanthines, particularly theobromine, may increase HDLconcentration in blood (Neufingerl et al., 2013), having been postulated that the mechanism of action involves increased levels of apolipoprotein A-1 and is independent of its activity as an adenosine receptor inhibitor (Monteiro et al., 2016; Monteiro et al., 2019). It is also important to highlight the properties of methylxanthines in counteracting hyperglycaemia and insulin resistance. This hypoglycemic effect is explained by the ability of these compounds to regulate intracellular levels of cAMP, with the release of insulin by $\beta$-pancreatic cells and glucose by the liver being dependent on this second messenger (Monteiro et al., 2016).

To end, the anti-inflammatory properties of methylxanthines should also be emphasized. While caffeine is able to inhibit the expression of tumour necrosis factor (TNF)- $\alpha$ by suppressing the cyclic-adenosine monophosphate/protein kinase $A$ (cAMP/PKA) pathway and inhibiting cAMP phosphodiesterase (Horrigan, Kelly \& Connor, 2004) no variation in the production of interleukin (IL)-1 $\beta$, IL-12 and IL-10 has been observed in human studies (Horrigan, Kelly \& Connor, 2004; Loftfield et al., 2015, Haskó \& Cronstein, 2011). In the case of theobromine, a decrease in IL-1 $\beta$ levels was reported in studies conducted in vitro (Fuggetta et al., 2019) and in mice (CampsBossacoma et al., 2019). In contrast, in humans, no studies with theobromine and 
504 inflammatory markers other than C-reactive protein (CRP) were found. However, two

505 studies, one carried out in moderate hypercholesterolemic and in healthy subjects

506 (Sarriá et al., 2014), observed a decrease in the serum levels of IL-1 $\beta$ and IL-10 after

507 consumption of a cocoa product rich in fibre, so we cannot rule out a synergistic effect

508 between the two bioactive compounds (Goya et al., 2016).

509 According to these results on methylxanthine metabolites, 7-methylxanthine (the main 510 cocoa methylxanthine metabolite) and theobromine may be responsible for the

511 antiinflammatory (decrease of IL-1 $\beta$ ) and hypoglycemic effects observed after the 512 intervention with DFC.

513

514 Dietary fiber

515 The remaining bioactive compound in cocoa products, dietary fibre, has certainly played 516 a role on the cardiovascular related effects observed. The different intake of dietary

517 fibre, with DFC (over $10 \mathrm{~g} / \mathrm{d}$ ) and PC (less than $4 \mathrm{~g} / \mathrm{d}$ ) may be related to the decrease in 518 glucose $(p=0.029)$ levels observed only after regularly consuming DFC, but not PC 519 (Heiss, Keen \& Kelm, 2010). This result is in agreement with the significant decrease in 520 plasma glucose concentration $(p=0.019)$ observed in a previous study carried out with a 521 dietary fibre-rich cocoa product (Sarriá et al., 2012), where the mechanisms responsible 522 for this effect were suggested to be that dietary fibre rich foods delay glucose absorption 523 from the small intestine (Glacco et al., 2000) and improve insulin sensitivity (Tokede,

524 Gaziano \& Djoussé, 2011). since it is well known that dietary fiber rich foods delay

525 glucose absorption from the small intestine and improve insulin sensitivity (Sarriá et al, 526 2015). However, the higher dietary fibre intake with DFC did not increase HDL-

527 cholesterol, in contrast to results described by Jenkins et al., (2000) who reported a 528 significant increase in HDL-cholesterol after consumption a cocoa-bran (25 g DF/d) for 529 two weeks in healthy subjects.

530 The effects of DFC on inflammation may be related to the down-regulation of cytokine 531 gene expression and up-regulation of the expression of scgb1a1, gene that codifies a 532 protein related to anti-inflammation, in the colon tissue (Massot-Cladera et al, 2017), as 
533 observed in rats that consumed either a cocoa diet or a cocoa fiber diet. In addition to

534 the positive effects on inflammation and glucose, DFC also produced positive

535 gastrointestinal effects such as an increased number of daily bowel movements and

536 reduced time to have a bowel movement, without inducing major adverse

537 gastrointestinal symptoms (Sarriá et al, 2012).

538 This study presents the following limitations and strengths: the bioavailability and 539 chronic studies were carried out separately, using different cocoa products although

540 they were produced by the same manufacturer and the cocoa matrix was quite similar.

541 However, it is relevant that health outcomes of chronic cocoa consumption in humans

542 are related to the cocoa's composition taking into account the bioavailability of the main

543 bioactive components, also evaluated in a human study. As aforementioned, no

544 previous studies, to our knowledge, have considered this integrative and associative

545 approach. Both the chronic and bioavailability studies are well designed and they have

546 been carried out in an adequate number of subjects with similar characteristics using

547 realistic amounts of cocoa. Moreover, the present work has been accomplished

548 knowing that a dose-dependent response occurs with both polyphenols and

549 methylxanthines, when the cocoa products were consumed at realistic doses, and the

550 metabolites obtained are the same disregarding the different quantities of the bioactive

551 components in cocoa products studied. It is pertinent to further investigate the results

552 here presented, so that in future chronic cocoa studies in humans a bioavailability study

553 will be performed in a subgroup of volunteers.

554

555 Conclusions

556 After the regular consumption of both DFC and PC, positive changes were observed in

557 volunteer's lipid profile, which may be related to the long-lasting presence of colonic

558 phenolic metabolites (headed by 5-(4'-hydroxyphenyl)-y-valerolactone-3'-sulfate) in

559 blood. In contrast, the anti-inflammatory and hypoglycemic effects were only observed

560 with DFC, and these may be related to methylxanthine metabolites, particularly 7-

561 methylxanthine which was the main cocoa methylxanthine metabolite, and theobromine,

562 and it is likely that insoluble dietary fibre may have also played a role. 
563

564

565

566

567

568

569

570

571

572

573

574

575

576

577

578

579

580

581

582

583

584

585

586

587

588

589

590

\section{Acknowledgements}

We are grateful to volunteers participating in the study. All authors revised and approved the final version of the manuscript.

\section{References}

\section{Appeldoorn M M, Vincken J P, Aura A M, Hollman P C, Gruppen H. 2009.}

Procyanidin dimers are metabolized by human microbiota with 2-(3 4-dihydroxyphenyl) acetic acid and 5-(3 4-dihydroxyphenyl)-y-valerolactone as the major metabolites.

Journal of Agricultural and Food Chemistry 57:1084-1092

Arranz S, Valderas-Martinez P, Chiva-Blanch G, Casas R, Urpi-Sarda M, LamuelaRaventós RM, Estruch R. 2013. Cardioprotective effects of cocoa: clinical evidence from randomized clinical intervention trials in humans. Molecular Nutrition and Food Research 57:936-947

\section{Baba S, Natsume M, Yasuda A, Nakamura Y, Tamura T, Osakabe N, Kanegae M,} Kondo K. 2007. Plasma LDL and HDL cholesterol and oxidized LDL concentrations are altered in normo- and hypercholesterolemic humans after intake of different levels of cocoa powder. Journal of Nutrition 137:1436-1441

Benzie IF, Szeto YT. 1999. Total antioxidant capacity of teas by the ferric reducing/antioxidant power assay. Journal of Agricultural and Food Chemistry 47:633636

Borges G, Ottaviani JI, Van der Hooft JJJ, Schroeter H, Crozier A. 2018. Absorption metabolism distribution and excretion of (-)-epicatechin: A review of recent findings. Molecular Aspects of Medicine 61:18-30

Bravo L, Saura-Calixto F. 1998. Characterization of the dietary fiber and the in vitro indigestible fraction of grape pomace. American Journal of Enology and Viticulture 49:135-141 
591 Camps-Bossacoma M, Garcia-Aloy M, Saldaña-Ruiz S, Cambras T, González592 Domínguez R, Franch A, Pérez-Cano FJ, Andres-Lacueva C, Castell M. 2019. Role 593 of theobromine in cocoa's metabolic properties in healthy rats. Journal of Agriculture 594 and Food Chemistry 6:3605-3614

595 Carlin-Sinclair A, Marc I. 2009. The determination of methylxanthines in chocolate and 596 cocoa by different separation techniques: HPLC instrumental TLC and MECC. Journal 597 of Laboratory Chemical Education 86:1307-1310

598 Cocoa - Food and Agriculture Organization of the United Nations 599 http://www.fao.org/3/y5143e/y5143e0x.htm

600 Cremonini E, Bettaieb A, Haj F G, Fraga C G, Oteiza P I. 2016. (-)-Epicatechin 601 improves insulin sensitivity in high fat diet-fed mice. Archives of Biochemistry and 602 Biophysics 599:13-21

603 Dower JI, Geleijnse JM, Gijsbers L, ZockPL, Kromhout D, Hollman PCH. 2015. 604 Effects of the pure flavonoids epicatechin and quercetin on vascular function and 605 cardiometabolic health: a randomized double-blind placebo-controlled crossover trial. 606 American Journal of Clinical Nutrition 101:914-921

607 Ellam S, Williamson G. 2013. Cocoa and human health Annual Review of Nutrition $608 \quad 33: 105-128$

609 Fogliano V, Corollaro M L, Vitaglione P, Napolitano A, Ferracane R, Travaglia F, 610 Arlorio M, Costabile A, Klinder A, Gibson G. 2011. In vitro bioaccessibility and gut 611 biotransformation of polyphenols present in the water-insoluble cocoa fraction.

612 Molecular Nutrition and Food Research 55:S44-55

613 Fuggetta MP, Zonfrillo M Villivà, C Bonmassar, E, Ravagnan G. 2019. Inflammatory

614 Microenvironment and Adipogenic Differentiation in Obesity: The Inhibitory Effect of

615 theobromine in a model of human obesity in vitro. Mediators of Inflammation 1515621

616 Giacco R, Parillo M, Rivellese A A, Lasorella G, Giaco A, D’Episcopo L, Ricardi J.

617 2000. Long-term dietary treatment with increased amounts of fiber-rich low-glycemic 
618 index natural foods improves blood glucose control and reduces the number of

619 hypoglycaemic events in type 1 diabetic patients. Diabetes Care 23:1461-1466

620 Gómez-Juaristi M, González-Torres L, Bravo L, Vaquero MP, Bastida S, Sánchez-

621 Muniz FJ. 2011. Beneficial effects of chocolate on cardiovascular health. Nutrición

622 Hospitalaria 26:289-292

623 Gómez-Juaristi M, Sarriá B, Martínez-López S, Bravo-Clemente L, Mateos R. 2019.

624 Flavanol bioavailability in two cocoa products with different phenolic content. A

625 comparative study in humans. Nutrients 11:1441

626 Goya L, Martín M, Sarriá B, Ramos S, Mateos R, Bravo L. 2016. Effect of cocoa and 627 its flavonoids on biomarkers of inflammation: studies of cell culture animals and 628 humans. Nutrients 8:212

629 Grassi D, Necozione S, Lippi C, Croce G Valeri L Pasqualetti P Desideri G

630 Blumberg JB Ferri C. 2005. Cocoa reduces blood pressure and insulin resistance and 631 improves endothelium-dependent vasodilation in hypertensives. Hypertension 46:398632405

633 Haskó G, Cronstein B. 2011. Methylxanthines and inflammatory cells. Handbook of 634 Experimental Pharmacology (200):457-468

635 Heiss C, Keen CL, Kelm M. 2010. Flavanols and cardiovascular disease prevention. 636 European Heart Journal 31:2583e2592

637 Hooper L, Kroon PA, Rimm EB, Cohn JS, Harvey I, Le Cornu KA, Ryder JJ, Hall 638 WL, Cassidy A. 2012. Effects of chocolate, cocoa, and flavan-3-ols on cardiovascular 639 health: a systematic review and meta-analysis of randomized trials. American Journal of 640 Clinical Nutrition 95:740-751

641 Horrigan LA, Kelly JP, Connor TJ. 2004. Caffeine suppresses TNF-a production via 642 activation of the cyclic AMP/protein kinase A pathway. International Immunopharmacology $643 \quad 4: 1409-1417$

644 Huang D, Ou B, Hampsch-Woodill M, FlanaganJA, Prior RL. 2002. High-throughput 645 assay of oxygen radical absorbance capacity (ORAC) using a multichannel liquid 
646 handling system coupled with a microplate fluorescence reader in 96-well format.

647 Journal of Agricultural and Food Chemistry 50:4437-4444

648 Jenkins DJA, Kendall CWC, Vuksan V, Vidgen E, Wong E, Augustin LS, Fulgoni V.

649 2000. Effect of cocoa bran on low-density lipoprotein oxidation and fecal bulking.

650 Archives of Internal Medicine 160:2374-2379

651 Josic J, Olsson AT, Wickeberg J, Lindstedt S, Hlebowicz J. 2010 Does green tea

652 affect postprandial glucose insulin and satiety in healthy subjects: A randomized

653 controlled trial. Nutrition Journal 9:63

654 Khan N, Monagas M, Andres-Lacueva C, Casas R, Urpi-Sarda M, Lamuela-

655 Raventos RM, Estruch R. 2012. Regular consumption of cocoa powder with milk

656 increases HDL cholesterol and reduces oxidized LDL levels in subjects at high-risk of

657 cardiovascular disease. Nutrition Metabolism and Cardiovascular Disease 22:1046-

6581053

659 Lecumberri E, Mateos R, Izquierdo-Pulido M, Ruperez P, Goya L, Bravo L. 2007.

660 Dietary fibre composition, antioxidant capacity and physico-chemical properties of a

661 fibre-rich product from cocoa (Theobroma cacao L.). Food Chemistry 104:948-954

662

663 Loftfield E, Shiels MS, Graubard BI, Katki HA, Chaturvedi AK, Trabert B, Pinto LA, 664 Kemp TJ, Shebl FM, Mayne ST, Wentzensen N, Purdue MP, Hildesheim A, Sinha

665 R, Freedman ND. 2015. Associations of coffee drinking with systemic immune and 666 inflammatory markers. Cancer Epidemiology Biomarkers Prevention 24:1052-1060

667 Martínez-López S, Sarriá B, Gómez-Juaristi M, Goya L, Mateos R, Bravo-Clemente

668 L. 2014a. Theobromine, caffeine, and theophylline metabolites in human plasma and 669 urine after consumption of soluble cocoa products with different methylxanthine 670 contents. Food Research International 63:446-455

671 Martínez-López S, Sarriá B, Sierra-Cinos J L, Goya L, Mateos R, Bravo L. 2014b.

672 Realistic intake of a flavanol-rich soluble cocoa product increases HDL-cholesterol 
673 without inducing anthropometric changes in healthy and moderately

674 hypercholesterolemic subjects. Food and Function 5:364-374

675 Massot-Cladera M, Franch À, Castell M, Pérez-Cano FJ. 2017. Cocoa polyphenols and 676 fiber modify colonic gene expression in rats. European Journal of Nutrition 56:1871-1885

677 Mellor DD, Sathyapalan T, Kilpatrick E S, Beckett S, Atkin S L. 2010. High-cocoa 678 polyphenol-rich chocolate improves HDL cholesterol in Type 2 diabetes patients.

679 Diabetic Medicine 27:1318-1321

680 Miller KB, Hurst WJ, Flannigan N, Ou B, Lee CY, Smith N, Stuart DA. 2009. Survey 681 of commercially available chocolate- and cocoa-containing products in the United 682 States. 2. Comparison of flavan-3-ol content with nonfat cocoa solids total polyphenols 683 and percent cacao. Journal of Agricultural and Food Chemistry 57:9169-9180

684 Monagas M, Urpi-Sarda M, Sánchez-Patán F, Llorach R, Garrido I, Gómez685 Cordovés Andrés-Lacueva C, Bartolomé B. 2010. Insights into the metabolism and 686 microbial biotransformation of dietary flavan-3-ols and the bioactivity of their 687 metabolites. Food and Function 1:233-253

688 Monteiro J, Alves M, Oliveira P, Silva B. 2016. Structure-bioactivity relationships of 689 methylxanthines: Trying to make sense of all the promises and the drawbacks.

690 Molecules 21:974

691 Monteiro J, Alves MG, Oliveira PF, Silva BM. 2019. Pharmacological potential of 692 methylxanthines: Retrospective analysis and future expectations. Critical Reviews in 693 Food Science and Nutrition 59:2597-2625

694 Neufingerl N, Zebregs YE, Schuring EA, Trautwein EA. 2013. Effect of cocoa and 695 theobromine consumption on serum HDL-cholesterol concentrations: a randomized 696 controlled trial. American Journal of Clinical Nutrition 97:1201-1209

697 Ottaviani Jl, Kwik-Uribe C, Keen CL, Schroeter H. 2012b. Intake of dietary 698 procyanidins does not contribute to the pool of circulating flavanols in humans. 699 American Journal of Clinical Nutrition 95:851-858 
700 Ottaviani JI, Momma TY, Kuhnle GK, Keen CL, Schroeter H. 2012a. Structurally 701 related (-)-epicatechin metabolites in humans: assessment using de novo chemically 702 synthesized authentic metabolites. Free Radical Biology and Medicine 52:1403-1412

703 Prakash M, Basavaraj BV, Murthy KC. 2019. Biological functions of epicatechin: Plant 704 cell to human cell health. Journal of Functional Foods 52:14-24

705 Pulido R, Bravo L, Saura-Calixto F. 2000. Antioxidant activity of dietary polyphenols 706 as determined by a modified ferric reducing/antioxidant power assay. Journal of 707 Agricultural and Food Chemistry 48:3396-3402

708

709

710

711

712

713

714

715

716

717

718 719

720

721

722

723

724

725

726 727

Re N, Pellegrini A, Proteggente A, Pannala A, Yang M, Rice-Evans C. 1999. Antioxidant activity applying an improved ABTS radical cation decolorization assay. Free Radical Biology and Medicine 26:1231-1237

Rodríguez-Mateos A, Weber T, Skene SS, Ottaviani Jl, Crozier A, Kelm M, Schroeter H, Heiss C. 2018. Assessing the respective contribution of dietary flavanol monomers and procyanidins in mediating cardiovascular effects in humans: randomized controlled double-masked intervention trial. American Journal of Clinical Nutrition 108:1229-1237

Rodriguez-Mateos AM, Vauzour D, Kreuger CG, Shanmuganayagam D, Reed D, Canali L, Mena P, Del Rio D, Crozier A. 2014. Flavonoids and related compounds bioavailability bioactivity and impact on human health: an update. Archives of Toxicology 88:1803-1853

Sarriá B, Martínez-López S, Fernández-Espinosa A, Gómez-Juaristi M, Goya L, Mateos R, Bravo L. 2012. Effects of regularly consuming dietary fibre rich soluble cocoa products on bowel habits in healthy subjects: a free-living two-stage randomized crossover single-blind intervention. Nutrition \& Metabolism 18:9-33

Sarriá B, Martínez-López S, Sierra-Cinos J L, García-Diz L, Mateos R, Bravo L. 2014. Regular consumption of a cocoa product improves the cardiometabolic profile in healthy and moderately hypercholesterolaemic adults. British Journal of Nutrition 111:122-134 
728 Sarriá B, Martínez-López S, Sierra-Cinos JL, Garcia-Diz L, Goya L, Mateos R,

729 Bravo L. 2015. Effects of bioactive constituents in functional cocoa products on

730 cardiovascular health in humans. Food Chemistry 174:214-218

731 Sarriá B, Mateos R, Sierra-Cinos JL, Goya L, García-Diz L, Bravo L. 2012.

732 Hypotensive hypoglycaemic and antioxidant effects of consuming a cocoa product in

733 moderately hypercholesterolemic humans. Food and Function 3:867-874

734 Saura-Calixto F, García-Alonso A, Goñi I, Bravo L. 2000. In vitro determination of the

735 indigestible fraction in foods: an alternative to dietary fiber analysis. Journal of

736 Agricultural and Food Chemistry 48:3342-3347

737 Saura-Calixto F, Goñi I. 2006. Antioxidant capacity of the Spanish Mediterranean diet.

738 Food Chemistry 94:442-447

739 Tokede OA, Gaziano JM, Djoussé L. 2011. Effects of cocoa products/dark chocolate

740 on serum lipids: a meta-analysis. European Journal of Clinical Nutrition 65:879-886

741 Urpi-Sarda M, Monagas M, Khan N, Lamuela-Raventos R M, Santos-Buelga C,

742 Sacanella E, Castell M, Permanyer J, Andres-Lacueva C. 2009a. Epicatechin

743 procyanidins and phenolic microbial metabolites after cocoa intake in humans and rats.

744 Analytical and Bioanalytical Chemistry 394:1545-1556

745 Urpi-Sarda M, Monagas M, Khan N, Llorach R, Lamuela-Raventós R M, Jáuregui $\mathbf{O}$

746 Andrés-Lacueva C. 2009b. Targeted metabolic profiling of phenolics in urine and

747 plasma after regular consumption of cocoa by liquid chromatography-tandem mass

748 spectrometry. Journal of Chromatography A 1216:7258-7267

749 Wan Y, Vinson JA, Etherton TD, Proch J, Lazarus SA, Kris-Etherton PM. 2001.

750 Effects of cocoa powder and dark chocolate on LDL oxidative susceptibility and

751 prostaglandin concentrations in humans. American Journal of Clinical Nutrition 74:596-

752602

753 Williams J F, Lowitt S, Polson J B, Szentivanyi A. 1978. Pharmacological and

754 biochemical activities of some monomethylxanthine and methyluric acid derivatives of

755 theophylline and caffeine. Biochemical Pharmacology 7:1545-1550 
756 World Cocoa Conference, 2018. https://www.icco.org/

757 Xing Y W, Lei G T, Wu Q H, Jiang Y, Huang MX. 2019. Procyanidin B2 protects

758 against diet-induced obesity and non-alcoholic fatty liver disease via the modulation of

759 the gut microbiota in rabbits. World Journal of Gastroenterology 25:955

760

761

762

763 
Figure 1

Bioactive compounds present in the cocoa products and the most abundant metabolites formed after flanavol and methylxanthine intake

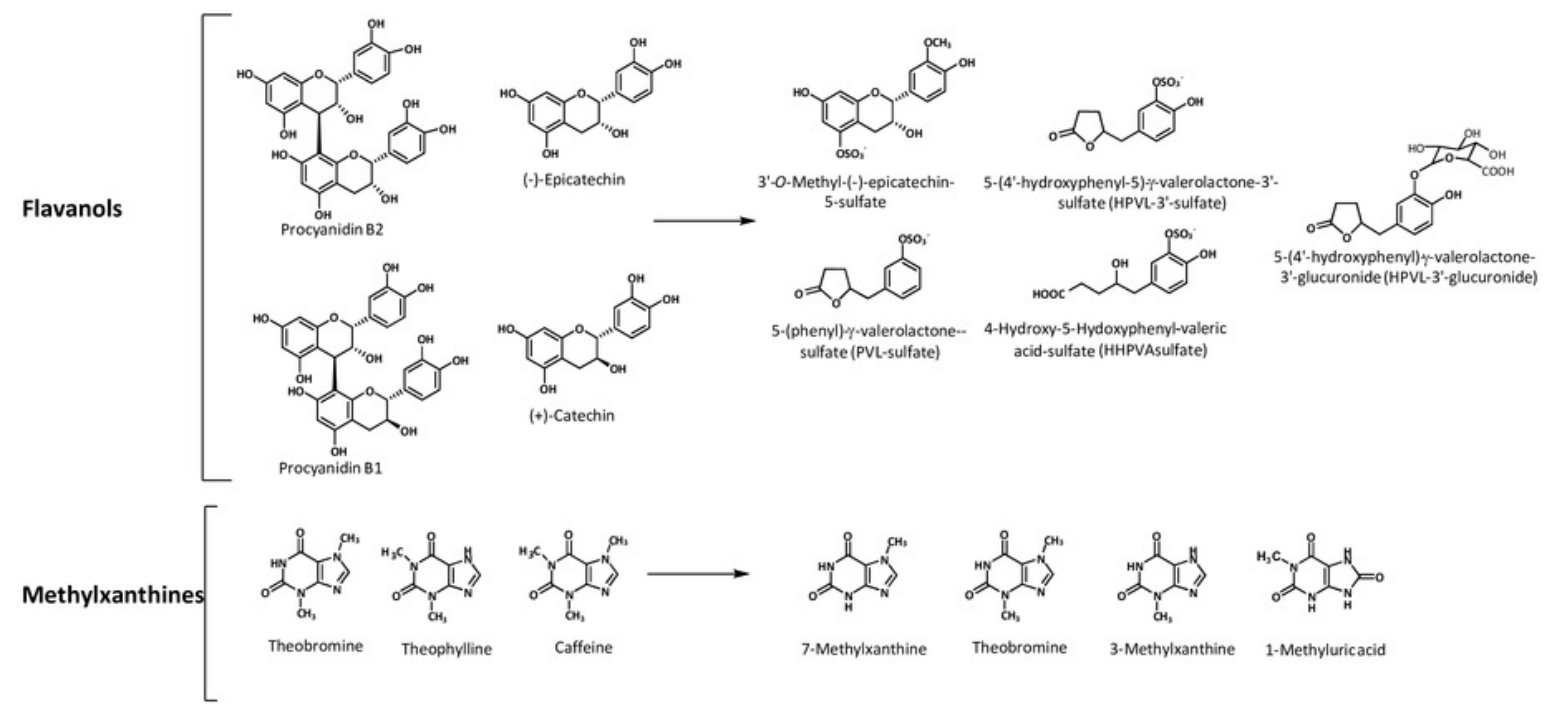




\section{Table $\mathbf{1}$ (on next page)}

Flavanols antioxidant activity dietary fibre and methylxanthines composition of the soluble cocoa products used in bioavailability and chronic interventions in humans: cocoa rich in cocoa (PC), cocoa rich in dietary fibre (DFC), conventional cocoa (CC), c 
1 Table 1. Flavanols antioxidant activity dietary fibre and methylxanthines composition of the

2 soluble cocoa products used in bioavailability and chronic interventions in humans: cocoa rich in 3 cocoa (PC), cocoa rich in dietary fibre (DFC), conventional cocoa (CC), cocoa rich in

4 methylxanthines and cocoa (MPC) and raw un-processed cocoa (RC).

\begin{tabular}{|c|c|c|c|c|c|}
\hline & Product PC & Product DFC & Product CC & Product MPC & Product RC \\
\hline \multicolumn{6}{|l|}{ Polyphenol composition } \\
\hline $\begin{array}{l}\text { Total Polyphenols }(a) \\
\text { ( } \mu \text { g equiv gallic acid /g product) } n=6\end{array}$ & $34.04 \pm 2.28$ & $15.75 \pm 0.67$ & $21.70 \pm 1.40$ & $25.63 \pm 1.00$ & $42.11 \pm 2.50$ \\
\hline EC (mg/g dry matter) (b) & $1.26 \pm 0.18$ & $0.33 \pm 0.09$ & $0.57 \pm 0.07$ & $1.15 \pm 006$ & $2.40 \pm 0.50$ \\
\hline CA ( mg/g dry matter ) (b) & $0.47 \pm 0.03$ & $0.26 \pm 0.12$ & $0.32 \pm 0.03$ & $0.53 \pm 0.04$ & $0.83 \pm 0.17$ \\
\hline PB1 ( mg/g dry matter ) (b) & $0.20 \pm 0.04$ & n.d. & $0.04 \pm 0.02$ & $0.23 \pm 0.02$ & $0.41 \pm 0.11$ \\
\hline PB2 ( mg/g dry matter ) (b) & $1.09 \pm 0.10$ & $0.57 \pm 0.11$ & $0.39 \pm 0.05$ & $0.82 \pm 0.06$ & $2.04 \pm 0.68$ \\
\hline Total flavanols (b) & $3.02 \pm 0.35$ & $1.16 \pm 0.32$ & $1.32 \pm 0.17$ & $2.73 \pm 0.18$ & $5.68 \pm 1.46$ \\
\hline
\end{tabular}

\begin{tabular}{|c|c|c|c|c|c|}
\hline \multicolumn{6}{|l|}{ Methylxanthines Composition } \\
\hline Theobromine (mg/g dry matter) (a) & $6.43 \pm 0.84$ & $5.11 \pm 0.14$ & $5.63 \pm 0.06$ & $7.08 \pm 0.22$ & $6.33 \pm 0.17$ \\
\hline Theophylline (mg/g dry matter) (a) & $0.01 \pm 0.01$ & n.d. & n.d. & $0.13 \pm 0.02$ & $0.06 \pm 0.01$ \\
\hline Caffeine (mg/g dry matter) (a) & $0.88 \pm 0.08$ & $0.51 \pm 0.05$ & $0.66 \pm 0.06$ & $3.03 \pm 0.28$ & $1.46 \pm 0.21$ \\
\hline Total methylxanthines & $7.32 \pm 0.93$ & $5.62 \pm 0.19$ & $6.29 \pm 0.12$ & $10.24 \pm 0.52$ & $7.85 \pm 0.39$ \\
\hline
\end{tabular}

\begin{tabular}{|c|c|c|c|c|c|}
\hline \multicolumn{6}{|l|}{ Dietary Fibre Composition } \\
\hline Soluble dietary fibre $(\%)=\mathrm{NS}+\mathrm{UA}$ & $3.13 \pm 0.59$ & $1.68 \pm 0.13$ & $2.69 \pm 0.70$ & $3.00 \pm 0.86$ & $4.27 \pm 0.27$ \\
\hline Neutral sugars (\%) & $2.46 \pm 0.43$ & $0.69 \pm 0.04$ & $2.21 \pm 0.51$ & $1.80 \pm 0.67$ & $2.70 \pm 0.14$ \\
\hline Uronic acid (\%) & $0.67 \pm 0.16$ & $0.99 \pm 0.09$ & $0.48 \pm 0.19$ & $1.20 \pm 0.19$ & $1.57 \pm 0.13$ \\
\hline Insoluble dietary fibre $(\%)=\mathrm{NS}+\mathrm{UA}$ & $11.96 \pm 1.05$ & $20.32 \pm 1.67$ & $14.31 \pm 0.51$ & $26.63 \pm 2.54$ & $11.58 \pm 1.30$ \\
\hline Neutral sugars (\%) & $10.49 \pm 0.96$ & $19.06 \pm 1.60$ & $13.32 \pm 0.29$ & $25.43 \pm 2.39$ & $9.12 \pm 1.08$ \\
\hline Uronic acid (\%) & $1.47 \pm 0.09$ & $1.26 \pm 0.07$ & $0.99 \pm 0.22$ & $1.20 \pm 0.15$ & $2.46 \pm 0.22$ \\
\hline Total dietary fibre $(\%)$ & $15.09 \pm 1.64$ & $22.00 \pm 1.80$ & $17.00 \pm 1.21$ & $29.63 \pm 3.40$ & $15.85 \pm 1.57$ \\
\hline
\end{tabular}

5 Analysis carried out using (a) Folin-Ciocalteau method (b) HPLC method (c) Bravo \& Saura-

6 Calixto, 1998. n.d.: not detected. EC: epicatechin; CA: catechin; PB1: procyanidin B1; PB2:

7 procyanidin $\mathrm{B} 2$ 


\section{Table 2 (on next page)}

Antioxidant activity of cocoa products rich in cocoa rich in cocoa (PC), cocoa rich in dietary fibre (DFC), conventional cocoa (CC), cocoa rich in methylxanthines and cocoa (MPC) and raw un-processed cocoa (RC). 
1 Table 2. Antioxidant activity of cocoa products rich in cocoa rich in cocoa (PC), cocoa rich in 2 dietary fibre (DFC), conventional cocoa (CC), cocoa rich in methylxanthines and cocoa (MPC) 3 and raw un-processed cocoa (RC).

4 $\begin{array}{lllll}\text { Product PC } & \text { Product DFC } & \text { Product CC } & \text { Product MPC } & \text { Product RC }\end{array}$

\begin{tabular}{|c|c|c|c|c|c|}
\hline \multicolumn{6}{|l|}{ Antioxidant activity } \\
\hline FRAP $(\mu \mathrm{mol} T E / \mu g$ product $) \mathrm{n}=3$ & $175.07 \pm 1.52$ & $75.88 \pm 2.61$ & $109.41 \pm 2.33$ & $120.12 \pm 3.26$ & $219.33 \pm 6.90$ \\
\hline ABTS ( $\mu \mathrm{mol}$ TE/g product) $n=3$ & $133.09 \pm 3.70$ & $56.64 \pm 3.26$ & $66.64 \pm 6.88$ & $89.53 \pm 2.99$ & $173.42 \pm 7.53$ \\
\hline ORAC ( $\mu \mathrm{mol} T E / g$ product $) \mathrm{n}=8$ & $459.71 \pm 9.40$ & $234.51 \pm 4.89$ & $248.56 \pm 4.32$ & $257.39 \pm 5.79$ & $483.93 \pm 19.88$ \\
\hline
\end{tabular}

5

6 


\section{Table 3 (on next page)}

Summary of the characteristics and outcomes of the cocoa bioavailability and chronic studies 
Table 3. Summary of the characteristics and outcomes of the cocoa bioavailability and chronic studies

\begin{tabular}{|c|c|c|c|c|c|}
\hline Reference & $\begin{array}{l}\text { Characteristics of } \\
\text { the study }\end{array}$ & $\begin{array}{l}\text { Number of } \\
\text { volunteers } \\
\text { and criteria }\end{array}$ & Cocoa product and dose & Main cocoa metabolites* & Health effects \\
\hline \multirow{4}{*}{$\begin{array}{l}\text { Gómez- } \\
\text { Juaristi et al. } \\
2019\end{array}$} & \multirow{4}{*}{$\begin{array}{l}\text { Polyphenol } \\
\text { bioavailability study } \\
\text { Randomized and } \\
\text { crossover, } 8 \text { hours } \\
\text { long carried out on } \\
\text { two separated days }\end{array}$} & \multirow{4}{*}{$\begin{array}{l}13 \\
\text { Healthy } \\
\text { subjects }\end{array}$} & \multirow{4}{*}{$\begin{array}{l}\text { Day 1: } 15 \mathrm{~g} \text { of conventional } \\
\text { cocoa }(C C)-19.80 \mathrm{mg} \text { of } \\
\text { flavanols/day } \\
\text { Day 2: } 25 \mathrm{~g} \text { of cocoa rich in } \\
\text { methylxanthines and phenols } \\
\text { (MPC) }-68.25 \mathrm{mg} \text { of } \\
\text { flavanols/day }\end{array}$} & $\begin{array}{l}\text { Plasma: Epicatechin and its phase II derivatives: 3'-Methyl- } \\
\text { epicatechin-5-sulfate, epicatechin-3'-sulfate, 4'-methyl- } \\
\text { epicatechin-5-sulfate, epicatechin-3'-glucuronide, among } \\
\text { others. }\end{array}$ & \multirow{3}{*}{$\begin{array}{l}\text { No changes in blood } \\
\text { pressure along the } 8 \\
\text { hours. } \\
\text { No changes in } \\
\text { antioxidant capacity in } \\
\text { blood along the } 8 \\
\text { hours, except } 1 \mathrm{~h} \\
\text { (ABTS) and } 2 \text { and } 8 \mathrm{~h} \\
\text { (FRAP) }\end{array}$} \\
\hline & & & & \multirow[t]{2}{*}{$\begin{array}{l}\text { 5-(3',4'-Dihydroxyphenyl)-- } \gamma \text {-valerolactone (DHPVL) and its } \\
\text { phase II derivatives (HPVL-3'-glucuronide, HPVL-3'-sulfate, } \\
\text { PVL-methyl-glucuronide). }\end{array}$} & \\
\hline & & & & & \\
\hline & & & & Dose-dependent response & \\
\hline \multirow{3}{*}{$\begin{array}{l}\text { Martínez- } \\
\text { López et al. } \\
2014 a\end{array}$} & \multirow{3}{*}{$\begin{array}{l}\text { Methylxanthine } \\
\text { bioavailability study } \\
\text { Randomized and } \\
\text { crossover, } 8 \text { hours } \\
\text { long carried out on } \\
\text { two separated days }\end{array}$} & \multirow{3}{*}{$\begin{array}{l}13 \\
\text { Healthy } \\
\text { subjects }\end{array}$} & \multirow{3}{*}{$\begin{array}{l}\text { Day 1: } 15 \mathrm{~g} \text { of conventional } \\
\text { cocoa (CC) - } 84.45 \mathrm{mg} \text { of } \\
\text { theobromine (TB) and } 9.9 \mathrm{mg} \text { of } \\
\text { caffeine (CF)/day } \\
\text { Day 2: } 25 \mathrm{~g} \text { of cocoa rich in } \\
\text { methylxanthines and phenols } \\
\text { (MPC) }-177 \mathrm{mg} \text { TB, } 75.75 \mathrm{mg} \\
\mathrm{CF} \text { and } 3.25 \mathrm{mg} \text { theophylline } \\
\text { (TP)/day }\end{array}$} & $\begin{array}{l}\text { Plasma: TB, CF, TP and paraxanthine (PX) together with two } \\
\text { monomethylxanthines (3-methylxanthine (MX) and 7-MX) }\end{array}$ & $\begin{array}{l}\text { No changes in blood } \\
\text { pressure along the } 8 \\
\text { hours. }\end{array}$ \\
\hline & & & & \multirow{2}{*}{$\begin{array}{l}\text { Urine: TB, CF, TP and PX, along with monomethylxanthines } \\
(1-\mathrm{MX}, 3-\mathrm{MX} \text { and } 7-\mathrm{MX}) \text { and different mono-, di- and tri- } \\
\text { methyluric (MU) acids (1-MU, 1,3-MU, 1,7-MU, 3,7-MU and } \\
1,3,7-\mathrm{MU}) .7-\mathrm{MX} \text { as the most abundant metabolite followed } \\
\text { by TB and 3-MX } \\
\text { Dose-dependent response }\end{array}$} & \\
\hline & & & & & $\begin{array}{l}\text { antioxidant capacity in } \\
\text { blood along the } 8 \\
\text { hours, except } 1 \mathrm{~h} \\
\text { (ABTS) and } 2 \text { and } 8 \mathrm{~h} \\
\text { (FRAP) }\end{array}$ \\
\hline
\end{tabular}


Randomized,

controlled and

crossover chronic

study. Cocoa and

control

interventions were

4 weeks long
$30 \mathrm{~g} /$ day ( 2 doses of $15 \mathrm{~g}$ of cocoa rich in dietary fiber (DFC)

44 subjects $\quad 34.8 \mathrm{mg}$ of flavanols/day

healthy

(n 24) and

moderately

hypercholest

erolemic ( $\mathrm{n}$

20)

$153.3 \mathrm{mg}$ of TB and $15.3 \mathrm{mg}$ of CF/day

$6.6 \mathrm{~g}$ total dietary fiber (DF)

$0.5 \mathrm{~g}$ soluble DF/day

$6.1 \mathrm{~g}$ insoluble DF/day

\section{Phenol metabolites according to Gómez-Juaristi et al.}

2019:

Epicatechin and phase II derivatives of epicatechin

Phase II derivatives of hydroxyphenyl- $y$-valerolactones and valeric acid

Methylxanthine metabolites according to Martínez-López et al. 2014a:

TB, CF, TP and paraxanthine (PX) together with monomethylxanthines (1-MX, 3-MX and 7-MX) and mono-, di- and tri-MU acids (1-MU, 1,3-MU, 1,7-MU, 3,7-MU and 1,3,7-MU)

Dietary fiber according to Sarriá et al. 2014. $\uparrow$ HDL-cholesterol

$\downarrow$ Blood glucose

$\uparrow I L-1 \beta$

$\downarrow$ IL-10

\section{Phenol metabolites according to Gómez-Juaristi et al.} 2019:

Epicatechin and phase II derivatives of epicatechin

Phase II derivatives of hydroxyphenyl-y-valerolactones and valeric acid
Randomized,

controlled and crossover-chronic study. Cocoa and control

interventions were

4 weeks long
44 subjects

(n 24) and

moderately

hypercholest erolemic $(n$

20)
$15 \mathrm{~g} /$ day $(2$ doses of $7.5 \mathrm{~g})$ of

$45.3 \mathrm{mg}$ of flavanols/day

$96.45 \mathrm{mg}$ of TB and $13.2 \mathrm{mg}$ of CF/day

$2.3 \mathrm{~g}$ total dietary fiber (DF)

$0.5 \mathrm{~g}$ soluble DF/day

$1.8 \mathrm{~g}$ insoluble DF/day

\section{Methylxanthine metabolites according to Martínez-López} et al. 2014a:

TB, CF, TP and PX together with monomethylxanthines and different mono-, di- and tri-MU acids.

\section{Dietary fiber}


*5-(3',4'-dihydroxyphenyl)- $\gamma$-valerolactone (DHPVL); 5-(4'-hydroxyphenyl)- $\gamma$-valerolactone (HPVL); 5-phenyl- $\gamma$-valerolactone (PVL); 4-hydroxy-5-(3',4'-dihydroxyphenyl)valeric acid (HDHPVA) and 4-hydroxy-5-(hydroxyphenyl)valeric acid (HHPVA).

$$
1
$$


Table 4 (on next page)

Antioxidant capacity in serum samples along the bioavailability study using ABTS and FRAP methods 
1 Table 4. Antioxidant capacity in serum samples along the bioavailability study using ABTS and FRAP methods

\begin{tabular}{|c|c|c|c|c|c|c|c|c|}
\hline \multicolumn{9}{|c|}{ ABTS ( $\mu \mathrm{M}$ TE) } \\
\hline Hours & 0 & 0.5 & 1 & 2 & 3 & 4 & 6 & 8 \\
\hline $\mathrm{CC}$ & $3830.59 \pm 114.35$ & $3682.88 \pm 112.79$ & $3605.06 \pm 81.59^{b}$ & $3658.54 \pm 94.03$ & $3696.70 \pm 91.70$ & $3665.45 \pm 97.03$ & $3687.98 \pm 82.26$ & $3797.14 \pm 108.21$ \\
\hline \multirow[t]{3}{*}{ MPC } & $3944.78 \pm 62.59$ & $3913.31 \pm 65.85$ & $3953.47 \pm 49.67^{a}$ & $3860.47 \pm 61.00$ & $3831.18 \pm 58.11$ & $3873.56 \pm 63.21$ & $3828.77 \pm 45.97$ & $3815.37 \pm 73.11$ \\
\hline & N.S. & N.S. & $p=0.004$ & N.S. & N.S. & N.S. & N.S. & N.S. \\
\hline & \multicolumn{8}{|c|}{ FRAP $(\mu \mathrm{M}$ TE) } \\
\hline Hours & 0 & 0.5 & 1 & 2 & 3 & 4 & 6 & 8 \\
\hline $\mathrm{CC}$ & $592.82 \pm 28.14$ & $579.43 \pm 32.27$ & $551.75 \pm 24.63$ & $540.19 \pm 26.67$ & $550.39 \pm 24.61$ & $550.49 \pm 27.44$ & $556.48 \pm 31.65$ & $530.39 \pm 24.16$ \\
\hline MPC & $596.70 \pm 23.77$ & $597.63 \pm 22.09$ & $580.28 \pm 22.50$ & $583.84 \pm 23.20$ & $578.61 \pm 23.43$ & $566.25 \pm 26.51$ & $583.85 \pm 26.35$ & $560.42 \pm 28.83$ \\
\hline & N.S. & N.S. & N.S. & $p=0.039$ & N.S. & N.S. & N.S. & $\mathrm{p}=0.044$ \\
\hline
\end{tabular}

